\title{
YESUS SAHABAT PEMUNGUT CUKAI DAN ORANG BERDOSA
}

\author{
Brury Eko Saputra
}

\begin{abstract}
Abstrak: Penelitian terdahulu terhadap Lukas 7:34 sangat fokus pada elemen struktural, teologis dan etis dari teks tersebut. Seiring dengan berkembangnya penelitian terhadap tema persahabatan, secara umum di dunia Greco-Roman dan, dan khususnya dalam kekristenan mula-mula, artikel ini berusaha mencoba membaca Lukas 7:34 dalam konteks tersebut.
\end{abstract}

Kata Kunci: Tradisi Persahabatan, Persahabatan Greco-Roman, Persahabatan Yahudi, Persahabatan Perjanjian Baru

Abstract: Previous studies on Luke 7:34 have primarily focused on the structural, theological, and ethical elements of the given text. In line with the emerging researches on the theme of friendship in the Greco Roman world and Early Christianity, this article attempts to read Luke 7:34 in light of those researches.

Keywords: Friendship Tradition, Greco-Roman Friendship, Jewish Friendship, New Testament Friendship

\section{TAFSIRAN UMUM LUKAS 7:34}

Dalam Lukas 7:34, Yesus merangkum pandangan sebagian orang terhadap diriNya; bahwa Ia adalah sahabat pemungut cukai dan orang berdosa. Meskipun identifikasi Yesus sebagai sahabat orang berdosa sangat menarik untuk dicermati dan menimbulkan banyak pertanyaan, tidak banyak ahli menyoroti hal tersebut. 
Joseph A. Fitzmyer berpendapat bahwa frasa tersebut mengkomunikasikan "a token of the freedom of the kingdom" secara sosial yang disalahpahami oleh banyak orang. ${ }^{1}$ John Nolland mengungkapkan bahwa identifikasi Yesus sebagai sahabat pemungut cukai dan orang berdosa oleh banyak orang terjadi karena kesalahpahaman orang di masa itu tentang anugerah Allah bagi orang berdosa yang ditunjukkan oleh Yesus melalui pelayananNya. ${ }^{2}$ Menurut Darrell L. Bock, penulis Injil Lukas hendak menunjukkan sebuah kontras gaya hidup dan pelayanan antara Yohanes Pembaptis yang disebut "kerasukan setan" (7:33) dan Yesus yang disebut sahabat para pendosa (7:34). ${ }^{3}$ François Bovon melihat frasa sahabat pemungut cukai dan orang berdosa merujuk pada kasih karunia Allah kepada orang termarjinal di tengah masyarakat melalui pelayan Yesus yang disalahpahami orang pada masaNya. ${ }^{4}$

Secara singkat, dapat dikatakan bahwa beberapa ahli di atas sangat fokus pada elemen struktural, teologis, dan etis dari Lukas 7:34. Para ahli tersebut tidak memberikan perhatian khusus kepada kata "sahabat", dalam frasa "sahabat pemungut cukai dan orang berdosa", di dalam relasinya dengan Tradisi Persahabatan di dalam Perjanjian Baru, Yudaisme maupun Greco-Roman. Artikel ini mencoba membaca rujukan terhadap kata "sahabat" dalam Lukas 7:34 dalam relasinya dengan konteks persahabatan Greco-Roman dan Yahudi pada masa itu.

1 Joseph A. Fitzmyer, The Gospel According to Luke I-IX: Introduction, Translation, and Notes (The Anchor Bible, Vol. 28), (New York: Doubleday, 1974), 681.

2 John Nolland, Luke 1:1-9:20 (Word Biblical Commentary Vol. 35a), (Dallas: Word Books, 1989), 340, 344-5.

${ }^{3}$ Darrell L. Bock, Luke 9:51-24:53 (Baker Exegetical Commentary on the New Testament), (Grand Rapids: Baker Academic, 1996), 683.

${ }^{4}$ François Bovon, Luke 1: A Commentary on the Gospel of Luke 1:1-9:50 (Hermeneia: A Critical \& Historical Commentary on the Bible), (Minneapolis: Augsburg Fortress, 2002), 287. 


\section{TRADISI PERSAHABATAN GRECO-ROMAN}

Dalam dunia Yunani konsep dan praktik persahabatan telah ada, bahkan, sejak masa Homer (dua karya yang paling banyak dikutip tentang topik ini adalah Iliad dan Odyssey). ${ }^{5} \mathrm{Di}$ dalam karya-karya Homer, tema persahabatan tidak ditampilkan secara formal semata, ${ }^{6}$ tetapi sangat operatif dengan adanya tindakan seperti berbagi kepemilikan, maupun perasaan saling mengasihi. ${ }^{7}$ Kenyataan ini membuat Arthur W. H. Adkins menyimpulkan, dalam penelitiannya terhadap tema persahabatan dalam tulisan Homer, bahwa persahabatan dalam Homer hanya dapat dimengerti dengan utuh dalam relasinya dengan masyarakat yang menjunjung tinggi nilai persahabatan pada masa itu. ${ }^{8}$ Dengan kata lain, karya Homer bukanlah fiksi semata, tetapi cerminan masyarakat yang memiliki nilai persahabatan yang bersifat operatif dan afektif. Selain itu, menurut catatan Sean Winter, Homer juga memberikan

5 Lih. David Konstan, Friendship in the Classical World, (Cambridge: Cambridge University Press, 1997), 24-52.

6 Konstan mencatat bahwa ada banyak sarjana modern berpendapat bahwa konsep dan praktik persahabatan di dalam karya Homer hanya bersifat formal dan dipenuhi motif mencari keuntungan semata, bahkan bersifat parasitik. Setelah melakukan penelitian terhadap kata-kata yang berhubungan dengan persahabatan dalam karya-karya Homer, Konstan berpendapat bahwa konsep dan praktek persahabatan dalam karya Homer sangat menekankan aspek aksi yang sangat didorong oleh afeksi. Lih. Konstan, Friendship, 24-25, 28-40; "Greek Friendship", in The American Journal of Philology, Vol. 117, No. 1, (1996): 7194.

7 John T. Fitzgerald, "Friendship in the Greek World Prior to Aristotle," in Greco-Roman Perspectives on Friendship, (Florida: SBL, 1997), 15-21; 15-21. Sean Winter, "Friendship Traditions in the New Testament: An Overview", in Pacifica, Vol. 29 Issue 2, (2016), 194, 198; Konstan, Friendship, 28-40; Konstan berpendapat bahwa kata philia dapat diterjemahkan sebagai friendship, love atau bahkan loving relationship. Meskipun demikian, ada banyak bukti dari tulisantulisan Yunani yang menegaskan bahwa orang Yunani kuno, dalam batasan tertentu, dapat membedakan ketiganya sebagaimana orang modern. Lih. Konstan, Friendship, 24-25, 28-40, 67-72.

8 Arthur W. H. Adkins, "'Friendship' and 'Self-Sufficiency' in Homer and Aristotle", in The Classical Quarterly Vol. 13, No. 1, (1963): 30-6. 
indikasi bahwa persahabatan berhubungan dengan divine realmsebagai hadiah dari para dewa. ${ }^{9}$

Tradisi persahabatan dalam dunia Yunani klasik juga dapat ditemukan dalam tulisan-tulisan Plato maupun Aristoteles. Di dalam bukunya yang berjudul Socrates on Friendship and Community, Mary P. Nichols menjawab kritikan Kierkegaard dan Nietzsche atas ide persahabatan dan komunitas dalam tulisantulisan Plato. ${ }^{10}$ Menurut temuannya, di dalam Symposium, Plato hendak menyampaikan bahwa pemahaman tentang kasih yang tertanam dalam rasa saling membutuhkan antara [sesama] manusia mempengaruhi seluruh aspek hidup dan relasi manusia. ${ }^{11}$ Perwujudan dari konsep tersebut adalah manusia menyadari keadaannya sebagai mahluk "in-between," sehingga ia harus bergantung kepada sesamanya untuk saling memenuhi satu sama lain. $^{12}$

Di dalam Phaedrus yang kaya akan diskusi retorika, metafiska dan pengetahuan, Plato juga memunculkan ide tentang persahabatan dalam konteks kasih. Nichols memberikan catatan bahwa "...by the time he [Plato] wrote the Phaedrus love triumphs over tragedy."13 Lebih lanjut, Nichols berkomentar bahwa di dalam Phaedrus, ada konsep "the lover and beloved whom Socrates describes as friends and who can see themselves in each other

\footnotetext{
${ }^{9}$ Winter, "Friendship Traditions", 196.

10 Mary P. Nichols, Socrates on Friendship and Community: Reflections on Plato's Symposium, Phaedrus, and Lysis, (Cambridge: Cambridge University Press, 2009), 7-24.

${ }^{11}$ Nichols, Socrates on Friendship, 30.

${ }^{12}$ Nichols menjelaskan demikian: "Socrates knows his own ignorance, and thus the imperfection of his knowledge, he also recognizes his affinity with his fellow humanity. In his "in-between" state, between knowledge and ignorance, Socrates depends on others for sustenance, and nurtures them in turn." Lih. Nichols, Socrates on Friendship, 31

${ }^{13}$ Nichols, Socrates on Friendship, 92.
} 
share the same type of human soul." ${ }^{14}$ Sederhananya, di dalam kompleksitas karya Phaedrus, Plato tidak melupakan elemen sosial yang sangat penting yaitu relasi persahabatan yang berhubungan erat dengan afeksi (dalam bahasa Plato: kasih) yang juga membawa pada pengetahuan dan retorika yang utuh.

Di dalam karyanya, Lysis, yang paling banyak dikutip karena membahas topik persahabatan secara eksplisit dan ambigu pada saat yang bersamaan, ${ }^{15}$ Plato menempatkan Sokrates dalam diskusi tentang persahabatan bersama dengan dua anak muda di Palaestra (gymnasium). Nichols dalam pembacaannya yang sangat positif terhadap Lysis mengungkapkan bahwa filsafat harus dipahami seperti persahabatan, ${ }^{16}$ di mana persahabatan bersifat timbal balik ("reciprocal; it requires that our friend love us in return") dan memberikan kesadaran bahwa seseorang adalah milik sahabatnya, tetapi pada saat yang bersamaan ia adalah milik dirinya sendiri. ${ }^{17}$ Dengan demikian, seorang sahabat pasti memiliki pengalamannya sebagai seorang individu, tetapi juga pengalamannya yang terbagi bersama sahabatnya. ${ }^{18}$ Menurut Nichols, pengalaman persahabatan yang demikian dapat diperluas kecakupan komunitas lainnya dalam

\footnotetext{
${ }^{14}$ Nichols, Socrates on Friendship, 94.

15 Salah satu kebingungan yang ditimbulkan Plato di dalam Lysis adalah pada saat bersamaan menampilkan Sokrates sebagai teman dari dua anak muda di Palaestra (frasa yang digunakan: "three go together"), tetapi juga yang mengatakan "we have not yet been able to discover what a friend is"

16 Kasih terhadap seorang sahabat berbeda dari kasih terhadap benda yang didasarkan pada banyak premise, tetapi kasih terhadap sahabat didasarkan pada kebutuhan yang membara (passionate). Kasih seperti itulah yang mendasari seseorang berfilsafat (philosophia; love for wisdom). Lih. Eugene Garver, "The Rhetoric of Friendship in Plato's Lysis," in Rhetorica: A Journal of the History of Rhetoric, Vol. 24, No. 2, (2006), 138; Nichols, Socrates on Friendship, 15; Mary P. Nichols, "Friendship and Community in Plato's 'Lysis",, in The Review of Politics, Vol. 68, No. 1, (2006): 3-13.

17 Garver, "The Rhetoric," 137-138; Nichols, Socrates on Friendship, 154; "Friendship and Community," 4-13.

${ }^{18}$ Cf. Nichols, Socrates on Friendship, 154.
} 
sebuah masyarakat, sehingga membentuk friendly society. ${ }^{19}$ Dengan demikian, dapat disimpulkan bahwa konsep persahabatanyang menekankan aspek timbal baik, serta otonomi dan kebergantung pada saat yang bersamaan-dalam Lysis, meskipun ambigu dan menimbulkan banyak perdebatan, adalah rujukan bagi filsafat, retorika, pengetahuan, dan hidup dalam komunitas.

Secara tradisional, para ahli berpendapat bahwa ada tiga hal ${ }^{20}$ yang tekait erat dengan konsep persahabatan ${ }^{21}$ dalam tulisan-tulisan Aristoteles (khususnya buku VIII-IX dari Nicomachean Ethics; juga di dalam Eudemian Ethics dan Magna Moralia), yaitu: utility, pleasure, dan virtue/character. ${ }^{22}$ Dalam pembacaannya terhadap Aristoteles, Verboven berpendapat bahwa persahabatan yang didasarkan pada utility dan pleasure bertahan sampai pada batasan adanya keuntungan atau kenikmatan dari persahabatan tersebut; oleh karena itu persahabatan atas dasar virtue dianggap utama. ${ }^{23}$ Meskipun demikian, persahabatan atas dasar virtue tidaklah

\footnotetext{
${ }^{19}$ Nichols, "Friendship and Community", 17-9.

${ }^{20}$ Konstan menyebut tiga sumber bagi philia (lih. Konstan, Friendship, 72) dan ahli lain menyebut tiga jenis persahabatan dengan dasar yang berbeda (lih. Koenraad Verboven, "Friendship among the Romans", in The Oxford Handbook of Social Relations in the Roman World, ed. Michael Peachin, [Oxford: Oxford University Press, 2011], 404; Bradley Bryan, "Approaching Others: Aristotle on Friendship's Possibility”, in Political Theory, Vol. 37, No. 6, [2009]: 757-60).

21 Komentator seperti Konstan berpendapat bahwa Aristotles dengan jelas membedakan antara hubungan friendship dengan fellow-citizens dan family members. Perbedaan paling jelas ada pada grounds atau dasar dari relasi tersebut. Lih. Konstan, Friendship, 67-72

${ }^{22}$ Konstan, Friendship, 72; Verboven, "Friendship," 404; Bradley Bryan dalam artikelnya berusaha membantah konsep tradisional ini dan membuktikan bahwa tidak ada tiga hal tentang (atau tipe) persahabatan, tetapi hanya ada satu saja persahabatan yang sejati yaitu "perfected friendship" (friendship that has reached it telos). Lih. Bryan, "Approaching Others," 754-79.

${ }^{23}$ Menurut Elena Irrera, ketiga "jenis" persahabatan tersebut memiliki derajat yang sama sebagai dasar persahabatan yang sejati jika memenuhi ketiga kondisi berikut: well-wishing, reciprocity dan awareness of the reciprocal love. Lih. Elena Irrera, "Between Advantage and Virtue: Aristotle's Theory of Political Friendship", in History of Political Thought Vol. 26, No. 4, (2005): 578.
} 
otomatis menjadi realita dalam kehidupan karena adanya konflik antara ide persahabatan tersebut dengan realita yang sedang dihidupi. ${ }^{24}$ Menurut Konstan, ketiga hal yang diungkapkan di atas adalah elemen penting dalam membentuk relasi persahabatan yang sesungguhnya. ${ }^{25}$ Sejalan dengan pandangan tersebut, Irrera menambahkan bahwa ketiga hal tersebut harus diikat dengan wellwishing, reciprocity dan awareness of the reciprocal love agar persahabatan sejati dapat terbentuk. ${ }^{26}$

Secara umum, ada dua tradisi persahabatan yang sangat mendominasi dunia intelektual Greco-Roman ${ }^{27}$ pada abad pertama, yaitu tradisi Epicurus dan tradisi Stoic. ${ }^{28}$ Menurut aliran Epicurus, persahabatan lahir dari kebutuhan dasar manusia untuk berada bersama dengan sesamanya. ${ }^{29}$ Bagi pengikut Epicurus, hanya manusia primitif yang tidak memiliki kebutuhan untuk berelasi (dalam persahabatan) dengan orang lain. ${ }^{30}$ Para penulis selanjutnya, seperti Cicero (De finibus 1.66-70), Philodemus (on candor), Diogenes of Oenoanda, dan lainnya melihat peran seorang sahabat sebagai penuntun kepada "keselamatan" dengan cara memberikan kritikan, serta menerima kritikan demi tujuan yang baik. ${ }^{31}$ Bagi Stoic, persahabatan yang sejati lahir sebagai respons terhadap nilai

\footnotetext{
${ }^{24}$ Verboven, "Friendship," 404.

${ }^{25}$ Konstan, Friendship, 72-8.

${ }^{26}$ Irrera, "Between Advantage," 578.

${ }^{27}$ Menurut Konstan, meskipun Bahasa Latin memiliki kata yang spesifik untuk persahabatan (amicitia), tradisi Romawi tentang persahabatan sangat dipengaruhi oleh tradisi Yunani. Dengan demikian, adalah tepat menyebut tradisi tersebut sebagai tradisi Greco-Roman. Lih. Konstan, Friendship, 122-4.

${ }^{28}$ Verboven, "Friendship", 404-5.

${ }^{29}$ Teks Epicurus yang sering dikutip adalah Sent. Vat. 23: "All philia is a virtue in itself, but draws its origin from assistance." Lih. Verboven, "Friendship," 404; Oleh karena itu, menariknya, dalam tulisan-tulisan Epicurus, philoi kerap kali merujuk pada sebuah relasi yang menginspirasi lahirnya confidence dan peace of mind. Lih. Konstan, Friendship, 111.

${ }^{30}$ Konstan, Friendship, 110-1.

${ }^{31}$ Konstan, Friendship, 112-3.
} 
(virtue) yang luhur, ${ }^{32}$ sehingga persahabatan hanya dapat ditemukan (dengan relatif lebih mudah) di kalangan orang yang memiliki keluhuran atau sage (lih. Diog. Laert. 7.124; band. Cic. De amicitia 5.18; Sen. Ep. Mor. 9.5-6). ${ }^{33}$

Berdasarkan survei singkat terhadap tradisi persahabatan di dalam dunia Greco-Roman, dapat disimpulkan ada beberapa hal penting yang terus muncul, yaitu: 1) Persahabatan adalah kebutuhan eksistensial manusia yang tidak sama dengan kebutuhan terhadap fellow-citizens maupun family members. Kebutuhan ini didasari oleh perasaan kasih dan afeksi yang kuat, sehingga menempatkan seseorang pada dua dunia (dunianya sendiri dan dunia sahabatnya). 2) Persahabatan yang sejati didasarkan pada keinginan yang besar untuk saling (reciprocity) mewujudkan kebaikan kepada orang lain (sahabat) dengan berbagai cara, termasuk memberikan kritikan dan menerima kritikan. 3) Persahabatan yang sejati tidak bersifat parasitik, terlihat dari ekspresi kasih dan ketulusan, serta pengorbanan seseorang bagi sahabatnya. Oleh karena itu, kesetian dan rasa saling percaya sangatlah penting dalam hubungan persahabatan.

\section{TRADISI PERSAHABATAN DALAM YUDAISME}

Menurut Winter, penelitian terhadap latarbelakang tradisi persahabatan dalam Perjanjian Baru jangan dibatasi hanya pada sumber-sumber Greco-Roman saja, tetapi juga dapat diperluas ke tradisi Yahudi. ${ }^{34}$ Dari sumber-sumber Yahudi tersebut, seorang

\footnotetext{
${ }^{32}$ Verboven, "Friendship", 404.

${ }^{33}$ Konstan, Friendship, 113; Dalam hal ini, menurut Cicero, meskipun dasar bagi persahabatan yang sejati adalah virtue (virtus) namun persahabatan dapat hadir dalam kalangan viri boni berupa vera et perfecta amicitia dan di kalangan boni berupa amicitia vulgaris/mediocris. Lih. Willy Evenepoel, "Cicero's Laelius and Seneca's letters on friendship", in L'Antiquité Classique, T. 76, (2007), 178.

${ }^{34}$ Winter, "Friendship Traditions", 193.
} 
peneliti akan mendapatkan lebih banyak kejelasan dan petunjuk tentang tradisi persahabatan yang muncul dalam Perjanjian Baru. ${ }^{35}$

Dalam beberapa tahun terakhir, ada sejumlah karya diterbitkan terkait dengan tema persahabatan dalam tradisi Yahudi. Pertama, sebuah disertasi diterbitkan pada tahun 2002 oleh Jeremy Corley dengan judul "Ben Sira's Teaching on Friendship." ${ }^{36}$ Dalam buku tersebut, Corley membahas tema persahabatan di dalam tujuh bagian kitab Ben Sira, yaitu: di bab dua teks Sir. 6:5-17 dan 37:1-6, bab tiga Sir. 9:10-16, bab empat Sir. 13:15-23, bab lima Sir. 19:1317 dan 27:16-2, dan bab enam Sir. 22:19-26. Setelah melakukan studi yang mendalam tersebut, Corley menyimpulkan bahwa Ben Sira meneruskan Tradisi Persahabatan dalam Perjanjian Lama, tetapi dengan modifikasi berdasarkan pertemuannya dengan budaya sekitar, seperti Yunani dan Mesir. ${ }^{37}$ Beberapa elemen penting tentang persahabatan yang dapat ditemukan dalam Ben Sira adalah tema tentang the goodness of friendsdhip, ${ }^{38}$ caution in friendship, ${ }^{39}$ faithfulness toward friends, ${ }^{40}$ dan the fear of God. ${ }^{41}$

\footnotetext{
${ }^{35}$ Winter, "Friendship Traditions", 196.

36 Jeremy Corley, Ben Sira's Teaching on Friendship, (Providence: Brown University, 2002).

${ }^{37}$ Corley, Ben Sira's Teaching, 213.

${ }^{38}$ Menurut Corley, elemen the goodness of friendship lahir dari usaha penulis Ben Sira di dalam mengombinasikan ide tentang $\varphi$ i $\lambda$ í $\alpha$ dalam tulisan Aristoteles (Lih. Eth. Nic. 9.9.3) dan teologi penciptaan Yahudi. Singkatnya, menurut Ben Sira, persahabatan adalah suatu realita yang baik dari Allah (lih. Sir. 25; 40). Lih. Corley, Ben Sira's Teaching, 214.

${ }^{39}$ Selain ajaran tentang kebaikan dari persahabatan, Corley juga menemukan ada banyak peringatan diberikan oleh penulis Ben Sira tentang persahabatan. Di dalam banyak bagian (e.g. Sir. 6:7, 13; 31:1; 37:4), penulis Ben Sira memperingatkan bahwa ada persahabatan yang sungguh, tetapi ada juga orang tertentu bersahabat hanya karena kepentingan tertentu pula. Oleh karena itu, seorang yang hendak bersahabat dituntun untuk menguji calon sahabat maupun seseorang yang ia anggap sebagai sahabatnya. Lih. Corley, Ben Sira's Teaching, 214-6.

40 Menurut Ben Sira, kesetiaan terhadap seorang sahabat adalah obat bagi persahabatan tanpa kesetiaan yang berkembang pada saat itu. Dalam Sir. 6:1416, seorang sahabat yang setia digambarkan sebagai a strong shelter, beyond
} 
Karya kedua berasal dari Saul M. Olyan dengan bukunya yang berjudul "Friendship in the Hebrew Bible." 42 Menurut Olyan, persahabatan merupakan sebuah relasi intim yang melibatkan perasaan (biasanya disebut sebagai kasih), selain hubungan antar keluarga atau kerabat (e.g. Ulangan 13:7; Mazmur 55:14; Amsal 18:24). ${ }^{43}$ Di dalam penelitian tersebut, ada beberapa fitur unik dalam tradisi Yahudi yang berhasil diungkap, yaitu adanya perasaan saling memiliki, mengasihi, timbal baik (reciprocity), dilandasi oleh perjanjian (covenant), serta adanya rasa saling tanggung jawab terhadap satu sama lain (e.g. Mazmur 35:13-14). ${ }^{44}$ Beberapa fitur tersebut terlihat dari beberapa narasi penting di dalam Perjanjian Lama, seperti relasi antara Daud dan Yonatan. ${ }^{45}$ Di bab terakhir bukunya, Olyan cukup banyak memberikan ruang bagi Ben Sira, di mana menurutnya ada tiga peran sahabat yang diungkapkan dengan cukup jelas di dalam teks tersebut. Tiga peran tersebut adalah sebagai seorang penuntun (Sir. 40:23), sebagai pendamai dalam konteks perselisihan (Sir. 22.21-22; 27:21), dan sebagai penunjang kebutuhan (Sir. 14:13; 22:23). ${ }^{46}$ Selain itu, sama seperti temuan Corley, Olyan melihat adanya peringatan untuk senantiasa bersikap hati-hati atas kemungkinan seorang teman berubah menjadi musuh. ${ }^{47}$

price dan a bundle of the living. Ide seperti ini dapat ditemukan dengan mudah dalam Perjanjian Lama, seperti Am. 18:24, 20:6 dan juga dalam tulisan-tulisan Theognis (Theognis 209; 415-416) dan Xenophon (Cyr. 8.7.13). Lih. Corley, Ben Sira's Teaching, 216-7

${ }^{41}$ Takut akan Allah adalah tema yang sangat dominan dalam tulisan Ben Sira. Tema ini dihubungan dengan persahabatan, di mana menurut Ben Sira seorang yang sungguh takut kepada Tuhan akan menemukan seorang sahabat sejati (e.g. 25:7-11; 40:18-27). Lih. Corley, Ben Sira's Teaching, 217-8.

${ }^{42}$ Saul M. Olyan, Friendship in the Hebrew Bible, Anchor Yale Bible Reference Library, (New Haven: Yale University Press, 2017).

${ }^{43}$ Olyan, Friendship, 5-6, 11-37.

${ }^{44}$ Olyan, Friendship, 5-6, 38-60.

${ }^{45}$ Olyan, Friendship, 69-76.

${ }^{46}$ Olyan, Friendship, 87-94.

${ }^{47}$ Olyan, Friendship, 38-60. 
Selain buku-buku yang telah disebutkan di atas, ada beberapa artikel yang membahas topik ini. Winter dalam artikelnya, "Friendship Traditions" banyak mengutip karya Olyan namun juga memberikan catatan tambahan tentang contoh persahabatan antara Allah dan manusia. Menurutnya, dalam tradisi Yahudi, ada banyak contoh yang melukiskan bahwa Allah menjalin hubungan persahabatan dengan manusia. Dalam Yesaya 41:8 (bnd. 2 Tawarikh 20:7), Abraham disebut sebagai sahabat Allah karena perannya sebagai bapa Israel. Dalam Keluaran 33:11, Allah berbicara kepada Musa seperti kepada seorang sahabat karena relasi perjanjian keduanya. Beberapa teks lain seperti Ayub 16:21 dan Mazmur 25:14 juga membahas tema persahabatan dalam konteks perjanjian. ${ }^{48}$ Prinsip penting dalam persahabatan di dalam tradisi Yahudi adalah elemen Perjanjian (Covenant). ${ }^{49}$ Teks Wisdom of Solomon menegaskan klaim dalam 7:14 dan 8:18 di mana gambaran tentang persahabatan kerap kali dihubungkan dengan relasi yang intim dengan Allah atau Sang Hikmat. ${ }^{50}$

Dalam artikel yang berjudul A Friend's First Word in Job 4:2, Aron Pinker berusaha melihat percakapan, yang dalam kacamata kesarjanaan modern sangat kontroversial, antara Ayub dengan sahabatnya (dalam pasal 4) dalam kacamata persahabatan pada masa itu. ${ }^{51}$ Menurutnya, jauh dari pandangan umum bahwa Elifas adalah seorang kritikus Ayub di masa susahnya, Pinker

\footnotetext{
${ }^{48}$ Winter, "Friendship Traditions", 198.

49 Winter, "Friendship Traditions", 197. Menurutnya, relasi antara Rut dan Naomi dapat dikategorikan sebuah relasi yang "... re-direct the covenant treaty between God and Abraham/Israel towards the horizontal friendship between the two women" (band. Rut 1:16).

${ }^{50}$ Winter, "Friendship Traditions", 198.

51 Aron Pinker, "A Friend's First Word in Job 4:2", in Vêtus Testamentum 63 (2013), 78-88.
} 
melihat perkataan Ayub dalam 4:2 dapat direkonstruksi dan diterjemahkan sebagai berikut: ${ }^{52}$

(a) Should we be silent?



(b) Talking to you is a hardship,

(c) And who can control the words?

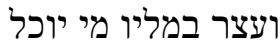

Dengan rekonstruksi demikian, maka pergerakan logis Ayub 4:2 menjadi (a) merupakan usaha Elifas meminta izin kepada Ayub untuk berbicara; (b) catatan tentang sulitnya untuk berkomunikasi dalam keadaan yang sulit; dan (c) alasan untuk kesulitan dalam hal komunikasi yang dimaksudkan. ${ }^{53}$ Dengan pembacaan demikian, pembaca Ayub mendapatkan kesan bahwa tindakan Elifas merupakan ekspresi kepedulian seorang sahabat terhadap sahabatnya yang menderita-seorang sahabat harus dapat mengendalikan perkataannya, tetapi pada saat yang bersamaan menyatakan perasaannya kepada sahabatnya. ${ }^{54}$

Bruce Waltke dalam sebuah artikel berjudul Friends and Friendship in the Book of Proverbs mencoba melakukan penelusuran terhadap ide persahabatan di dalam Amsal 27.55 Menurutnya, Amsal 27 dimaksudkan untuk memberikan penegasan tentang pentingnya memiliki seorang sahabat sejati, cara mengidentifikasinya, dan bagaimana cara menjadi seorang sahabat yang baik. ${ }^{56}$ Pada bagian pertama Amsal ini, ayat 1-10, ada beberapa nasihat terkait dengan persahabatan yang penting untuk dicermati: seorang sahabat harus memiliki kerendahatian di dalam

\footnotetext{
${ }^{52}$ Untuk diskusi soal persoalan tekstual dan proposal yang diusulkan ini, lih. Pinker, “A Friend's First", 80-7.

${ }^{53}$ Pinker, "A Friend's First", 87.

${ }^{54}$ Pinker, "A Friend's First", 87-8.

55 Bruce Waltke, "Friends and Friendship in the Book of Proverbs: An Exposition of Proverbs 27:1-22”, in CRUX Vol. XXXVIII, No 3 (2002): 27-42.

56 Waltke, "Friends and Friendship", 27.
} 
Jurnal Theologia Aletheia Volume 20 No.15 September 2018113 mendengarkan orang lain (ay. 1-2), ${ }^{57}$ menghindari pergaulan/persahabatan yang tidak bernilai rohani (ay. 3-4), ${ }^{58}$ berani memberikan koreksi terhadap seorang sahabat (ay. 5-6), ${ }^{59}$ menjaga relasi persahabatan [dan pernikahan] terhadap kebodohan yang akan menjatuhkan (ay. 7-8), ${ }^{60}$ dan senantiasa memberikan dukungan dan masukan bagi seorang sahabat (ay. 9-10). ${ }^{61}$ Pada bagian keduanya, ayat 11-21, ada beberapa nasihat yang ditekankan kembali, seperti kerendahatian untuk mendengar (ay. 11-12), menjauhi pergaulan yang tidak kudus (ay. 13-14), dan menghindari hal-hal yang dapat merusak persahabatan (ay. 15-16). ${ }^{62}$ Ada beberapa hal yang ditambahkan pada bagian kedua ini, yaitu persahabatan dan [jangan melewati] batasan dalam persahabatan (ay. 17-20) ${ }^{63}$ dan senantiasa mengevaluasi diri (ay. 21-22). ${ }^{64}$

Di dalam artikelnya yang berjudul Friends with God?, Jacqueline E. Lapsley melakukan eksplorasi ide tentang hubungan

\footnotetext{
${ }^{57}$ Waltke, "Friends and Friendship", 28-9.

${ }^{58}$ Waltke, "Friends and Friendship", 29-30.

${ }^{59}$ Waltke, "Friends and Friendship", 30-2.

${ }^{60}$ Waltke, "Friends and Friendship", 32-3.

${ }^{61}$ Waltke, "Friends and Friendship", 33-5.

${ }^{62}$ Waltke, "Friends and Friendship", 36-8.
}

${ }^{63}$ Di dalam artikelnya yang berjudul "Iron Sharpens Iron" as a Negative Image, Ronald L. Giese Jr berpendapat bahwa gambaran tentang besi dalam Amsal 27:17 bukanlah gambaran positif sebagaimana dipahami pada umumnya (sama seperti besi menajamkan besi, seorang sahabat memberikan nilai positif kepada sahabatnya). Menurutnya, gambaran besi menajamkan besi bersifat negatif dan dapat ditemukan dalam konteks peperangan di mana seorang perajurit menajamkan senjatanya dengan palu besi dengan tujuan berperang. Dengan demikian, ay. 13-17 dapat dimengerti secara kasual seperti ini "Take counsel, whether praise or rebuke, from other men you trust. But be about work, and planning, and investing. Don't spend too much time with a wife or with a male friend, since extended time leads not only to lack of work (laziness) but to nagging, unproductive conversation, or even the grinding or hammering of another person's personality, quirks, or opinions against one's own." Lih. Ronald L. Giese Jr, “'Iron Sharpens Iron' as a Negative Image: Challenging the Common Interpretation of Proverbs 27:17', in JBL 135, No. 1, (2016): 73-5

${ }^{64}$ Waltke, "Friends and Friendship", 38-41. 
antara friendship dan covenant. ${ }^{65}$ Menurutnya, relasi antara Allah dan umatNya di dalam Perjanjian Lama kerap kali dibandingkan dengan perjanjian di Timur Dekat Kuno yang mana "a sovereign enters into a highly structured relationship with a vassal". ${ }^{66}$ Dengan melihat hubungan antara Allah dengan Musa sebagai model, Lapsley berusaha menyelidiki kemungkinan adanya hubungan persahabatan antara Allah dan umatNya. ${ }^{67}$ Dalam penyelidikannya, Lapsley menemukan ada empat kualitas persahabatan yang sangat penting dalam relasi antara Allah dengan Musa. Keempat kualitas tersebut adalah habit, reciprocity, self-assertion dan emotion. ${ }^{68}$ Menurutnya, meskipun kualitas terakhir, emotion, adalah yang paling sering diabaikan, kemampuan mengekspresikan kasih secara emosional adalah bagian yang sangat penting dari persahabatanbaik Allah dengan Musa, maupun Allah dengan umatNya secara umum. ${ }^{69}$ Di akhir artikelnya, Lapsley menekankan kembali bahwa dasar bagi relasi antara Allah dan umatNya adalah Perjanjian (Covenant) yang terikat di antara keduanya. ${ }^{70}$

Selain beberapa karya yang menyelidiki tema tentang persahabatan dalam tradisi Yahudi di atas, seorang peneliti tidak dapat melepaskan pandangannya terhadap kisah persahabatan yang kontroversial dan inspiratif antara Daud dan Yonatahan di dalam Perjanjian Lama. Pada tahun 2012, Orly Keren memberikan sebuah ulasan yang menarik tentang relasi antara Daud dan Yonathan.

${ }^{65}$ Jacqueline E. Lapsley, "Friends with God? Moses and the Possibility of Covenantal Friendship", in Interpretation Vol. 58, Issue 2, (2004): 117-29.

${ }^{66}$ Lapsley, "Friends with God?", 117.

${ }^{67}$ Di dalam hubungan antara Allah dan Musa, Lapsley menemukan adanya intimasi yang personal-selayaknya ditemukan dalam persahabatan (dapat juga ditemukan di dalam relasi antara Allah dan Abraham)-di dalam percakapan percakapan pribadi keduanya (Kel. 33:7-11). Dasar bagi keintiman ini adalah adanya perjanjian (covenant) antara Allah dan Musa. Lih. Lapsley, "Friends with God?", 117-20.

${ }^{68}$ Lapsley, "Friends with God?", 121-7.

${ }^{69}$ Lapsley, "Friends with God?", 124-7.

${ }^{70}$ Lapsley, "Friends with God?", 127-9. 
Menurutnya, hubungan kedua tokoh dalam kitab Samuel tersebut tidak dapat dikatakan berlandaskan pada unconditional love, tetapi self-interest. Melalui relasi tersebut, lanjut Keren, Yonathan berharap supaya adanya kelangsungan dinastinya di kemudian hari, sementara bagi Daud relasinya dengan Yonathan akan memberikan public image yang positif baginya. ${ }^{71}$ Dari sudut pandang socialscience, ${ }^{72}$ Gary Stansell berpendapat bahwa relasi antara Daud dan Yonathan bukanlah relasi yang ascribed tetapi achieved; oleh karena itu, meskipun relasi mereka bersifat asymmetry (imbalance), tetapi tetap memiliki unsur reciprocity. ${ }^{73}$ Berbeda dari Keren, Stansell berpendapat bahwa relasi antara Daud dan Yonathan memiliki aspek ritual (ritualized friendship) yang menurut para antropolog menandakan sebuah relasi persahabatan yang sungguh dari sudut pandang social-science. ${ }^{74}$ Dalam bahasa Patricia K. Tull, aspek ritual ini diwujudnyatakan melalui gift dari seorang temandalam hal ini Yonathan kepada Daud. ${ }^{75}$

Berdasarkan survei singkat tentang karya-karya para ahli tentang tema persahabatan dalam tradisi Yudaisme dapat disimpulkan bahwa ada banyak elemen penting tradisi persahabatan Greco-Roman dapat juga ditemukan dalam tradisi

\footnotetext{
71 Orly Keren, "David and Jonathan: A Case of Unconditional Love?", in Journal for the Study of the Old Testament Vol. 71, Issue 1, (2012): 3-23.

72 Dalam hal ini, Stansell membedakan antara pendekatan Aristoteles yang ia sebut sebagai pendekatan dengan fokus pada "moral utilitarian," dengan pendekatan social-sience yang dikembangkan oleh Radcliffe-Brown. Dalam artikelnya, ia menggunakan pendekatan kedua tersebut. Lih. Gary Stansell, "David and His Friends: Social-Scientific Perspectives on the David-Jonathan Friendship", in Biblical Theology Bulletin Vol. 41 No. 3, (2011): 115-31.

73 Stansell, "David and His Friends",: 122-3.

${ }^{74}$ Stansell, "David and His Friends",: 123-4.

75 Patricia K. Tull, "Jonathan's Gift of Friendship", in Interpretation, Vol. 58, No 2, (2004): 133-7.
} 
Yudaisme. ${ }^{76}$ Sebagai kesimpulan, beberapa hal penting dan mendasar tentang persahabatan dalam tradisi Yudaisme adalah: 1) Persahabatan yang sejati, baik dengan Allah maupun umatNya, harus dilandaskan pada perjanjian (covenant); 2) Peran seorang sahabat digambarkan seperti peran hikmat di dalam kehidupan umat Allah (bnd. Ben Sira dan Wisdom of Salomon); 3) Seorang sahabat hadir dalam keadaan baik maupun buruk, serta mampu memberikan tuntunan maupun teguran pada saat yang bersamaan; 4) Hubungan persahabatan bersifat reciprocity dan penuh kasih (dengan berbagai ekspresi); dan 5) Umat Allah dinasihati untuk tidak salah memilih sahabat.

\section{TRADISI PERSAHABATAN DALAM PERJANJIAN BARU}

Banyak ahli menyadari bahwa tema tentang sahabat dapat ditemukan pada banyak bagian Perjanjian Baru. Berkenaan dengan surat-surat Paulus, ${ }^{77}$ para ahli berpendapat bahwa tema persahabatan dapat ditemukan dengan mudah di Surat kepada jemaat di Filipi (lih. 1:5, 7; 2:1-2; 4:2, 14, 15). ${ }^{78}$ Menurut Luke Timothy Johnson, setiap pembaca teks Yunani Koine Surat Filipi

\footnotetext{
76 Winter berpendapat bahwa persahabatan adalah kategori sosial, sehingga overlap antara tradisi persahabatan Greco-Roman dan Yudaisme sangatlah dapat dipahami. Lih. Winter, "Friendship Traditions", 198.

77 Dalam artikelnya, "Paul and Friendship," Fitzgerald memberikan sebuah list yang komprehensif tentang kemunculan tema persahabatan di dalam tulisan Paulus. Lih. John T. Fitzgerald, "Paul and Friendship", in J. Paul Sampley (ed.), Paul in the Greco-Roman World: A Handbook, (Harrisburg: Trinity Press International, 2003), 319-343.

${ }^{78}$ Beberapa ahli yang meniliti tema persahabatan dalam Surat Filipi adalah L. Michael White, "Morality Between Two Worlds: A Paradigm of Friendship in Philippians", in David L. Balch, Everett Ferguson and Wayne A. Meeks (eds.), Greeks, Romans, and Christians: Essays in Honor of Abraham J. Malherbe (Minneapolis: Fortress, 1990); Ben Witherington III, Friendship and Finances in Philippi: The Letter of Paul to the Philippians, (Harrisburg: Trinity Press International, 1994); dari sudut pandang feminis: Joseph A. Marchal, Hierarchy, Unity and Imitation: A Feminist Rhetorical Analysis of Power Dynamics in Paul's Letter to the Philippians-Academia Biblica 24, (Leiden: Brill/SBL, 2006).
} 
akan mendapatkan kesan bahwa teks tersebut berbicara tentang tema persahabatan. $^{79}$ Johnson menambahkan, keunikan tema persahabatan di Surat Filipi adalah penekanan pada pribadi Yesus yang berkorban dan memberi teladan. Oleh karena itu, jemaat Filipi harus dapat menerapkan pengalaman tersebut secara reciprocal dalam persahabatan mereka ${ }^{80}$ Menurut Winter, ada dua fitur utama dalam persahabatan di Surat Filipi, yaitu dukungan material dan finansial (lih. 4:10-20) serta menjauhkan diri dari musuh (lih. 3:2-3, $18-20) .{ }^{81}$

Selain Filipi, ada yang meyakini bahwa Surat Galatia juga mengindikasikan adanya tema persahabatan. Menurut L. Michael White penggunaan bahasa persahabatan di dalam Surat Galatia, yang menurut beberapa ahli hanyalah sebuah rhetorical device, adalah sebuah sebuah seruan dan teguran kepada sahabat yang telah "membagikannya" dan Injil yang ia beritakan. Dengan demikian, menurut White, Surat Galatia dapat dibaca sebagai seruan akan kebutuhan sahabat sejati dalam komunitas Paulus. ${ }^{82}$ Meskipun ditulis dalam konteks yang berbeda, kebutuhan akan sahabat yang bersedia menerima dan membantu sahabatnya juga dapat ditemukan dalam Roma 15:14-33 ketika Paulus mengutarakan rencana perjalanan pelayanannya ke depan. ${ }^{83} 1$ Korintus 16:1-4 juga menyuarakan hal yang sama terkait dengan

${ }^{79}$ Luke Timothy Johnson, "Making Connections: The Material Expression of Friendship in the New Testament", in Interpretation, Vol. 58, No 2, (2004), 1634; band. John Fitzgerald, "Christian Friendship: John, Paul, and the Philippians", in Interpretation, Vol. 61, No. 3, (2007):286-8.

${ }^{80}$ Johnson, "Making Connections", 162-5.

${ }^{81}$ Winter, Friendship Traditions", 200.

${ }^{82}$ L. Michael White, "Rhetoric and Reality in Galatians: Framing the Social Demands of Friendship," in Early Christianity and Classical Culture: Comparative Studies in Honor of Abraham J. Malherbe, (Leiden: Brill, 2003), 307-343; band. Winter, Friendship Traditions," 201; Johnson, "Making Connections", 165.

${ }^{83}$ Winter, Friendship Traditions", 201. 
persembahan yang berhasil dihimpunnya untuk jemaat di Yerusalem. ${ }^{84}$

Di luar tulisan Paulus, tema persahabatan dapat ditemukan dalam tulisan-tulisan Yohanes (dan Injil lainnya), Kisah Para Rasul, dan Surat Yakobus. Di dalam Injil Yohanes, Yesus ditampilkan sebagai seorang sahabat yang rela mati bagi sahabatNya dan tindakan lainnya yang nyata bagi sahabatNya. ${ }^{85} \mathrm{Di}$ dalam surat-surat Yohanes, motif persahabatan, seperti berbagi dan kasih (2 Yohanes 10; 3 Yohanes 8; 1 Yohanes 1:7, 3:16-18) dapat ditemukan juga dengan sangat jelas. ${ }^{86}$ Menurut Fitzgerald, persahabatan yang ditemukan di Yohanes sangat mirip, bahkan identik dengan deskripsi persahabatan yang muncul dalam tulisan Paulus. ${ }^{87}$ Hal serupa pun dapat dikatakan pada beberapa bagian dalam teks Kisah Para Rasul, seperti dalam 2:44-47 dan 4:32-37. Alan C. Mitchell berpendapat, dari kacamata sosiologis, tindakan yang bersifat reciprocal dalam kedua teks tersebut sangat erat kaitannya dengan tradisi persahabatan yang ada di Greco-Roman. ${ }^{88}$

${ }^{84}$ Johnson, "Making Connections", 166; Max J. Lee menambahkan bahwa dalam 1 Korintus, seorang pembaca juga dapat menemukan bahwa Paulus menempatkan dirinya sebagai seorang sahabat dengan peran mentoring terhadap jemaat di Korintus. Di dalam 1 Korintus Paulus kerap kali terlihat membimbing, memberikan pengertian, bahkan menegur jemaat di Korintus. Tujuan dari semuanya itu adalah adanya perkembangan aspek moral dari jemaat di Korintus. Lih. Max J. Lee, "Ancient Mentors and Moral Progress According to Galen and Paul", in Rebekah A. Eklund and John E. Phelan Jr. (eds.), Doing Theology for the Church: Essays in Honor of Klyne Snodgrass, (Oregon: Wipf \& Stock Publishers, 2014), 62-7.

${ }^{85}$ Gail R. O'Day, "Jesus as Friend in the Gospel of John", in Interpretation, Vol. 58, No. 2, (2004): 148-57.

86 Johnson, "Making Connections", 168-9.

${ }^{87}$ Fitzgerald, "Christian Friendship", 291.

88 Alan C. Mitchell, "The Social Function of Friendship in Acts 2:44-47 and 4:32-37', in Journal of Biblical Literature, Vol. 111, No. 2, (1992), 264-6; cf. Johnson, "Making Connections", 161-2. 
Berkenaan dengan Surat Yakobus, karya Alicia J. Batten dengan judul Friendship and Benefaction in James berhasil menunjukkan pentingnya tema persahabatan dalam surat tersebut dalam konteks dunia kuno. Menurut Batten, berdasarkan konteks sosialnya, Surat Yakobus ditulis untuk memberikan kesadaran akan bahaya aspek manipulatif dari hubungan patron-client yang jemaat miliki dengan golongan kaya-miskin dalam komunitas penerima surat. $^{89}$ Solusi untuk bahaya ini adalah menyadari adanya persahabatan sejati, yaitu persahabatan dengan Allah. ${ }^{90}$ Persahabatan dengan Allah yang sejati ini pada akhirnya harus dicerminkan dalam kehidupan sosial dengan memperhatikan sesama sebagai sahabat. ${ }^{91}$

Berdasarkan penelurusan singkat terhadap karya para ahli tentang kemunculan tema persahabatan di dalam Perjanjian Baru, terlihat jelas bahwa para penulis Perjanjian Baru sangat dipengaruhi oleh tradisi persahabatan Greco-Roman dan Yudaisme tentang: 1) Pesahabatan berhubungan dengan Allah (dimensi covenant), di mana persahabatan sejati hanya dapat diperoleh dalam relasi dengan Allah (adanya peringatan atas persahabatan yang tidak sejati); 2) Penekanan terhadap aspek reciprocity antar sahabat; 3) Adanya tendensi melalukan yang terbaik bagi seorang sahabat, meskipun melalui pengorbanan; 4) Kasih dan afeksi menjadi elemen yang penting dalam persahabatan; dan 5) Adanya penekanan pada peran/tanggung jawab (baik secara finansial, emosional, dan secara sosial) seorang sahabat terhadap sahabatnya.

${ }^{89}$ Alicia J. Batten, Friendship and Benefaction in James, (Blandford Forum: Deo Publishing, 2010), 56-89, 122-44.

${ }^{90}$ Batten, Friendship, 145-77.

${ }^{91}$ Lih. Batten, Friendship, 169-77; Johnson, "Making Connections", 169-70. 


\section{TRADISI PERSAHABATAN DALAM INJIL LUKAS}

Berdasarkan penelitiannya, Rollin Ramsaran menyimpulkan bahwa tema tentang persahabatan dalam Injil Lukas sangat jarang diperhatikan. ${ }^{92}$ Padahal, tema tentang persahabatan sangat kental di dalam Injil Lukas. ${ }^{93}$ Menurut Winter, kerap kali Injil Lukas memberikan indikasi adanya tema persahabatan dalam istilahistilah yang digunakan (e.g. 7:6; 14:10), namun sesungguhnya narasi dalam Injil Lukaslah yang menyiratkan banyak hal tentang persahabatan. $^{94}$ Ramsaran memberikan catatan bahwa di dalam narasi Lukas, pembaca dapat menemukan adanya tema bahwa Allah hadir sebagai seorang sahabat (e.g. 11:5-8) dan Yesus adalah model bagi sahabat yang sejati (e.g. 14:7-14; 15:1-31). ${ }^{95}$ Dalam penelitiannya terhadap Lukas, Mitchell dengan tepat mengatakan bahwa tema persahabatan di dalam Injil Lukas kerap kali menampilkan Yesus sebagai sahabat bagi orang-orang yang terpinggirkan (e.g. 6:34-35; 14:12-14). ${ }^{96}$ Hal ini senanda dengan

\footnotetext{
92 Rollin Ramsaran, "Who is the True Friend? Lukan Friendship as Paradigm for the Church", in Leaven, Vol. 5 Issue 2, (1997), 1; cf. Sean Winter, "Friendship Traditions in the New Testament: An Overview", in Pacifica, Vol. 29 Issue 2, (2016), 201-2.

${ }^{93}$ Kemunculan tema persahabatan dalam Injil Lukas sangat berhubungan dengan kemunculan tema yang sama di dalam tulisan Kisah Para Rasul. Lih. Winter, "Friendship Traditions", 201-2; Johnson, "Making Connections", 161-2; Mitchell, "The Social Function", 262-72.

${ }^{94}$ Winter, "Friendship Traditions", 201; cf. Alan C. Mitchell, "'Greet the Friends by Name:' New Testament Evidence for the Greco-Roman Topos on Friendship," in Greco-Roman Perspectives on Friendship, John T. Fitzgerald (ed.), (Florida: SBL, 1997), 236-57.

95 Dalam 11:5-8, kisah tentang seorang sahabat yang kekurangan makanan pada malam hari memberikan indikasi tentang relasi antara Allah dan umatNya dalam konteks doa dan permohonan; 14:7:14 menunjukkan sikap kepedulian Yesus terhadap kaum terpinggirkan; dan 15:1-31 menunjukkan kepedulian Yesus terhadap "yang terhilang" di mana ekspresinya yang muncul sangat erat dengan tema persahabatan Greco-Roman. Lih. Ramsaran, "Who is the True Friend?", 26-7

96 Mitchell, "The Social Function”, 266.
} 
pemikiran Greco-Roman yang menjadikan virtue, bukan sematamata kesetaraan material, sebagai dasar untuk bersahabat.

\section{Yesus Sahabat Pemungut Cukai dan Orang Berdosa (Lukas 7:34)}

Di dalam Lukas 7:34, Yesus merangkum pandangan umum sebagian orang tentang Diri-Nya dengan rujukan sebagai sahabat pemungut cukai dan orang berdosa ( $\dot{\alpha} \mu \alpha \rho \tau \omega \lambda \tilde{\omega} v)$. Rujukan tersebut sangat erat kaitannya dengan


dengan sifat rakus/pelahap [ $\varphi \alpha ́ \gamma o \varsigma]$ ) dan minum (sama seperti kata

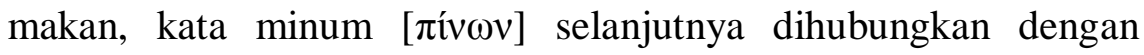
keadaan mabuk/peminum [oivo dalam pelayananNya. Pertanyaannya, mengapa aktivitas makan dan minum tersebut secara otomatis membuat Yesus diidentifikasikan sebagai seorang sahabat bagi pemungut cukai dan orang berdosa? Untuk menjawab pertanyaan ini, perhatian khusus harus diberikan pada kedua aktivitas tersebut dalam kaitannya dengan tradisi persahatan yang telah dibahas pada bagain sebelumnya dalam artikel ini.

Sebagaimana diungkapkan oleh Kylie Crabbe, saat ini para sarjana Injil Lukas sepaham bahwa kisah tentang makan (meal scenes) sangatlah penting di dalam menafsirkan Injil Lukas. ${ }^{97}$ Paling tidak, ada tujuh catatan yang jelas tentang Yesus menghadiri acara makan (meal) di dalam Injil Lukas (5:27-32; 7:36-50; 9:1017 ; 11:37-52; 14:1-24; 22:14-38; 24:28-32) dan dua catatan yang kemungkinan juga berhubungan dengan makan (10:38-42; 19:110). ${ }^{98}$ Crabbe memberikan catatan penting bahwa aktivitas makan

\footnotetext{
${ }^{97}$ Kylie Crabbe, “A Sinner and a Pharisee: Challenge at Simon's Table in Luke 7:36-50", in Pacifica 24, (2001), 247.

${ }^{98}$ Crabbe, "A Sinner and a Pharisee", 247.
} 
bersama dalam Lukas adalah usaha friendship-making yang sangat mirip dengan kisah-kisah makan bersama dalam Symposium Plato dan pada saat bersamaan menggemakan kembali kisah pemberian makan dari Allah (Kel. 16:13-21; 1 Raj. 17:1-16; 2 Raj. 4:38-44), serta undangan dariNya kepada umatNya dalam pesta yang besar (cf. Mzm. 23; Yes. 55:1-3; Am. 9:1-6). ${ }^{99}$

Persoalan utama dalam Lukas 7:34 tentunya bukan hanya pada aktivitas makan dan minum saja, tetapi pada orang-orang yang makan dan minum bersama dengan Yesus saat itu. Menurut catatan Kilgallen, Lukas dengan jelas memberikan beberapa rujukan bahwa Yesus makan dan minum bersama dengan pemungut cukai dan orang berdosa $(5: 30 ; 7: 34 ; 15: 2 ; 19: 7) .{ }^{100} \mathrm{Di}$ dalam pasal 5, aktivitas makan dan minum bersama pemungut cukai dan orang berdosa berhubungan erat dengan misi Yesus-sang Anak Manusia-yaitu memanggil orang yang berdosa pada pertobatan (5:32). ${ }^{101}$ Motif yang sama juga dapat ditemukan dalam pasal 7 dengan adanya penambahan elemen eskatologis tentang kedatangan mesias yang ditunggu oleh bangsa Israel (cf. 7:27); dalam hal ini kedatangan Yesus sebagai sahabat bagi pemungut cukai dan orang berdosa. ${ }^{102}$

Dalam 15:2 Yesus kembali ditampilkan makan bersama dengan orang berdosa. Dalam pasal tersebut, Yesus mengisahkan tiga buah perumpamaan yang mirip (perumpamaan tentang koin yang hilang, perumpamaan tentang domba yang hilang dan perumpamaan tentang anak yang hilang). Meskipun dalam kedua perumpamaan pertama, obyek yang hilang bersifat pasif (menunggu untuk ditemukan) dan pada perumpamaan yang ketiga

${ }^{99}$ Crabbe, "A Sinner and a Pharisee", 248-9.

${ }^{100}$ John Kilgallen, "Was Jesus Right to Eat with Sinners and Tax Collectors?", in Biblica, Vol. 93, No. 4, (2012): 590-600.

${ }^{101}$ Kilgallen, "Was Jesus Right", 591-3.

102 Kilgallen, "Was Jesus Right", 593-5. 
obyek yang hilang digambarkan sebagai figur yang aktif (dari perspektif tradisi persahabatan, keaktifan anak yang hilang dan penerimaan sang ayah merupakan elemen reciprocity yang penting), ketiga perumpamaan tersebut mengisahkan sukacita luar biasa karena ditemukannya obyek yang hilang. ${ }^{103}$

Pasal 19 tidak secara langsung memberikan referensi tentang makan dan minum, tetapi hanya pada interaksi antara Yesus dan pemungut cukai bernama Zakheus yang diidentifikasi sebagai orang berdosa (19:7). Meskipun demikian, informasi bahwa Yesus akan menginap di rumah Zakheus (19:5) memberikan indikasi bahwa aktivitas makan dan minum mungkin saja terjadi di rumah tersebut. ${ }^{104}$ Ada tiga hal menarik pada bagian akhir perikop ini yang perlu dicatat: 1) Yesus menyatakan keselamatan telah terjadi atas rumah Zakehus (19:9a); pernyataan ini sangat mirip dengan well-wishing dalam tradisi persahabatan Greco-Roman; 2) Rujukan terhadap Zakheus sebagai anak Abraham (19:9b) menyuarakan kembali elemen perjanjian (covenant) dalam tradisi persahabatan Yahudi; dan 3) Frasa Anak Manusia datang untuk mencari dan menyelamatkan yang hilang (19:10) memberikan kesan adanya elemen afeksi dan aksi sebagaimana dapat ditemukan dalam tradisi persahabatan Greco-Roman dan Yahudi.

Selain pertimbangan aktivitas makan dan minum bersama dengan pemungut cukai dan orang berdosa dalam perspektif tradisi persahabatan, hal penting yang perlu diperhatikan adalah kemunculan kata "hikmat" dalam 7:35. Kemunculan hikmat mengingatkan kembali akan gambaran persahabatan yang muncul dalam tulisan-tulisan Yahudi seperti Amsal, Mazmur, Wisdom of

103 Kilgallen, "Was Jesus Right", 595-7.

${ }^{104}$ Kilgallen, "Was Jesus Right", 597-8. 
Soloman, dan Ben Sira. ${ }^{105}$ Lukas 7:35 adalah respons Yesus terhadap identifikasi diriNya sebagai sahabat pemungut cukai dan orang berdosa. Dalam respons tersebut, Yesus tidak menolak disebut sebagai sahabat pemungut cukai dan orang berdosa, tetapi justu menyatakan bahwa apa yang Ia lakukan adalah benar dalam terang hikmat dan rencana Allah.

Dengan membaca Lukas 7:34 dalam perspektif tradisi persahabatan Greco-Roman dan tulisan Yahudi, frasa "sahabat pemungut cukai dan orang berdosa" merujuk pada: 1) Persahabatan antara Allah dan umatNya melalui kehadiran Yesus sebagai sahabat (dalam kasus Zakheus, aspek covenant ikut berperan); 2) Adanya dimensi reciprocity dan eskatologis dari aktivitas makan dan minum yang Yesus lakukan dengan pemungut cukai dan orang berdosa; 3) Ekspresi persahabatan melalui afeksi dan aksi terlihat jelas dalam kisah-kisah yang menceritakan aktivitas makan dan minum; 4) Adanya well-wishing terhadap sahabat sebagai wujudnyata rencana Allah bagi pemungut cukai dan orang berdosa; dan 5) Adanya referensi terhadap hikmat sebagaimana jelas dalam tradisi persahabatan Yahudi.

\section{Pembacaan Persahabatan terhadap Lukas 7:34 dan Horison Masa Kini}

Penelitian tentang tema dan praktik persahabatan telah menjadi area telaah banyak bidang studi (dan pendekatan, seperti pendekatan epistemis, eksistensial, maupun ontologis), seperti sosiologi, filsafat, etika, bisnis dan lain sebagainya. Salah satu contoh dari banyak studi tersebut adalah pembacaan Steve Garlick terhadap ide persahabatan yang muncul dalam tulisan-tulisan

${ }^{105}$ Cf. Winter, "Friendship Traditions", 198; Olyan, Friendship, 38-60; Corley, Ben Sira's Teaching 
Michel Foucault dalam relasinya dengan seni (art). ${ }^{106}$ Di bagian pendahuluan artikelnya, Garlick menyampaikan pemikiran Nietzsche tentang persahabatan dengan mengatakan "[T]hat is to say, a friend should be the enemy of all that is ugly and unhealthy in the other." 107 Dengan memperhatikan identifikasi Yesus sebagai sahabat pemungut cukai dan orang berdosa dalam terang konsep Nietzsche tentang persahabatan, maka pembaca hari ini dapat menangkap kesan bahwa tindakan well-wishing (bahkan kadangkadang dalam bentuk teguran) yang Yesus lakukan adalah usaha menjadi musuh bagi keburukan sahabatNya.

Berkenaan dengan relasi antara konsep sahabat dan art di dalam pemikiran Foucault, Garlick berkata:

Friendship as a work of art both brings into focus the importance of the relation to the other, and breaks down the distinction between producer and receiver, subject and object. ${ }^{108}$

Garlick menjelaskan lebih lanjut bahwa yang dimaksud dengan "breaks down the distinction" sebagai "the care of the self implies both relations with others and the care of others," sehingga "to create oneself as a beautiful friend for the other is always dependent upon responding to the other as other" 109 Dengan membuat relasi antara kesimpulan Garlick [dan Webb] terhadap ide

106 Steve Garlick, "The Beauty of Friendship: Foucault, Masculinity, and the Work of Art", in Philosophy and Social Criticism, Vol. 28, No. 5, (2002): 55877. Penulis tidak sepenuhnya sepaham dengan argumen dan kesimpulan Garlick, namun artikel ini hanya melihat beberapa hal yang bermafaat dan terkait dengan tulisan ini.

${ }^{107}$ Garlick, "The Beauty of Friendship", 559.

108 Garlick, "The Beauty of Friendship", 569.

109 Garlick, "The Beauty of Friendship", 569., cf. David Webb, "On Friendship: Derrida, Foucault, and the Practice of Becoming", in Research in Phenomenology 33, (2003): 119-38. 
persahabatan Foucault (persahabatan adalah "the complex system of power relations that condition who we are and how we can act") dengan identifikasi Yesus sebagai sahabat pemungut cukai dan orang berdosa, pengikut Yesus hari ini dapat menghayati persahabatan secara personal sebagai usaha mendefinsikan diri (siapakah Kristen itu?), serta bertindak (bagaimana seseorang dapat disebut Kristen?) dalam hubungan dengan orang lain. Jika diperluas, pembacaan Lukas 7:34 dari perspektif persahabatan juga dapat memberikan sumbangsih terhadap "conflict-trobled societies" dengan interaksi dengan "critical pedagogies of friendship" seperti digagas oleh Michalinos Zembylas. ${ }^{110}$ Masih ada banyak lagi relasi antara pembacaan persahabatan terhadap Lukas 7:34 dengan horison masa kini yang dapat dieksplorasi, namun hal tersebut perlu sebuah artikel khusus lagi. Meskipun demikian, penulis tetap hendak memberikan catatan bahwa pembacaan seperti ini akan memberikan peluang dan manfaat bagi pembaca hari ini, khususnya orang Kristen masa kini.

110 Michalinos Zembylas, "Derrida, Foucault and critical pedagogies of friendship in conflict-troubled societies", in Discourse: Studies in the Cultural Politics of Education, Vo. 36, No. 1, (2015): 1-14. Dalam artikel tersebut, ada beberapa hal yang perlu digarisbawahi tentang Ciritcal Pedagogies of Friendship yang juga dapat dijadikan rekan dialog bagi pembacaan Lukas 7:34 dalam perspektif persahabatan: First, an important feature of critical pedagogies of friendship grounded in Derrida's and Foucault's accounts is the emphasis on the acceptance of the other's singularity as a point of departure to engage students in compassion and solidarity with others (10); Second, critical pedagogies of friendship in conflict-troubled societies mark the possible within the impossible, that is, they set the cultural and social limits to the possibilities of relationality with the other, but, at the same time, they create openings for struggle and resistance against normative expectations, outside of exchange relations (11); Finally, another feature of critical pedagogies of friendship in conflict-troubled societies is that it encourages new understandings of 'community' and 'identity' that could work emotionally as more inclusive to others and that would go beyond binary categorizations of belonging (12). 


\section{KESIMPULAN}

Lukas 7:34 mencatat bahwa Yesus merangkum pandangan sebagain orang tentang diriNya sebagai sahabat pemungut cukai dan orang berdosa. Dengan membaca frasa tersebut dalam terang tradisi persahabatan Greco-Roman, Tulisan Yahudi, dan Perjanjian Baru, maka pembaca menyadari bahwa identifikasi tersebut dapat dihubungkan dengan persahabatan dengan Allah, adanya kepedulian Allah melalui Yesus secara afektif maupun reciprocal, serta well-wishing kepada seorang sahabat. Menariknya, pembacaan seperti ini membuka peluang serta dorongan bagi orang Kristen masa kini untuk menyatakan ke-diri-an mereka, serta kehadiran di tengah masyarakat sebagai seorang sahabat.

\section{DAFTAR RUJUKAN}

Adkins, Arthur W. H. '“Friendship' and 'Self-Sufficiency' in Homer and Aristotle", in The Classical Quarterly Vol. 13, No. 1, (1963).

Batten, Alicia J. Friendship and Benefaction in James. Blandford Forum: Deo Publishing, 2010.

Bock, Darrell L. Luke 9:51-24:53 (Baker Exegetical Commentary on the New Testament). Grand Rapids: Baker Academic, 1996.

Bovon, François. Luke 1: A Commentary on the Gospel of Luke 1:1-9:50 (Hermeneia: A Critical \& Historical Commentary on the Bible). Minneapolis: Augsburg Fortress, 2002.

Bryan, Bradley. "Approaching Others: Aristotle on Friendship's Possibility", in Political Theory, Vol. 37, No. 6, (2009).

Corley, Jeremy. Ben Sira's Teaching on Friendship. Providence: Brown University, 2002. 
Crabbe, Kylie. "A Sinner and a Pharisee: Challenge at Simon's Table in Luke 7:36-50", in Pacifica 24, (2001).

Evenepoel, Willy. "Cicero's Laelius and Seneca's letters on friendship", in L'Antiquité Classique, T. 76, (2007).

Fitzgerald, John T. "Friendship in the Greek World Prior to Aristotle", in Greco-Roman Perspectives on Friendship. Florida: SBL, 1997.

Fitzgerald, John T. "Paul and Friendship", in J. Paul Sampley (ed.), Paul in the Greco-Roman World: A Handbook. Harrisburg: Trinity Press International, 2003.

Fitzgerald, John T. "Christian Friendship: John, Paul, and the Philippians," in Interpretation, Vol. 61, No. 3, (2007).

Fitzmyer, Joseph A. The Gospel According to Luke I-IX: Introduction, Translation, and Notes (The Anchor Bible, Vol. 28). New York: Doubleday, 1974.

Garlick, Steve. "The Beauty of Friendship: Foucault, Masculinity, and the Work of Art", in Philosophy and Social Criticism, Vol. 28, No. 5, (2002).

Garver , Eugene. "The Rhetoric of Friendship in Plato's Lysis", in Rhetorica: A Journal of the History of Rhetoric, Vol. 24, No. 2, (2006).

Giese Jr, Ronald L. '“'Iron Sharpens Iron' as a Negative Image: Challenging the Common Interpretation of Proverbs 27:17', in JBL 135, No. 1, (2016).

Irrera, Elena. "Between Advantage and Virtue: Aristotle's Theory of Political Friendship", in History of Political Thought, Vol. 26, No. 4, (2005).

Johnson, Luke Timothy. "Making Connections: The Material Expression of Friendship in the New Testament", in Interpretation, Vol. 58, No 2, (2004).

Keren, Orly. "David and Jonathan: A Case of Unconditional Love?", in Journal for the Study of the Old Testament Vol. 71, Issue 1, (2012). 
Kilgallen, John. "Was Jesus Right to Eat with Sinners and Tax Collectors?", in Biblica, Vol. 93, No. 4, (2012).

Konstan David. "Greek Friendship", in The American Journal of Philology, Vol. 117, No. 1, (1996).

Konstan David. Friendship in the Classical World. Cambridge: Cambridge University Press, 1997.

Lapsley, Jacqueline E. "Friends with God? Moses and the Possibility of Covenantal Friendship", in Interpretation Vol. 58, Issue 2, (2004).

Lee, Max J. "Ancient Mentors and Moral Progress According to Galen and Paul", in Rebekah A. Eklund and John E. Phelan Jr. (eds.). Doing Theology for the Church: Essays in Honor of Klyne Snodgrass. Oregon: Wipf \& Stock Publishers, 2014.

Marchal, Joseph A. Hierarchy, Unity and Imitation: A Feminist Rhetorical Analysis of Power Dynamics in Paul's Letter to the Philippians - Academia Biblica 24. Leiden: Brill/SBL, 2006.

Mitchell, Alan C. "'Greet the Friends by Name:' New Testament Evidence for the Greco-Roman Topos on Friendship", in John T. Fitzgerald (ed.). Greco-Roman Perspectives on Friendship. Florida: SBL, 1997.

Mitchell, Alan C. "The Social Function of Friendship in Acts 2:4447 and 4:32-37", in Journal of Biblical Literature, Vol. 111, No. 2, (1992).

Nichols, Mary P. "Friendship and Community in Plato's 'Lysis"”, in The Review of Politics, Vol. 68, No. 1, (2006).

Nichols, Mary P. Socrates on Friendship and Community: Reflections on Plato's Symposium, Phaedrus, and Lysis. Cambridge: Cambridge University Press, 2009.

Nolland, John. Luke 1:1-9:20 (Word Biblical Commentary Vol. 35a). Dallas: Word Books, 1989. 
O'Day, Gail R. "Jesus as Friend in the Gospel of John", in Interpretation, Vol. 58, No. 2, (2004).

Olyan, Saul M. Friendship in the Hebrew Bible, Anchor Yale Bible Reference Library. New Haven: Yale University Press. 2017.

Pinker, Aron. "A Friend's First Word in Job 4:2", in Vêtus Testamentum 63, (2013).

Ramsaran, Rollin. "Who is the True Friend? Lukan Friendship as Paradigm for the Church", in Leaven, Vol. 5 Issue 2, (1997).

Stansell, Gary. "David and His Friends: Social-Scientific Perspectives on the David-Jonathan Friendship", in Biblical Theology Bulletin Vol. 41 No. 3, (2011).

Tull, Patricia K. "Jonathan's Gift of Friendship", in Interpretation, Vol. 58, No 2, (2004).

Verboven, Koenraad. "Friendship among the Romans", in The Oxford Handbook of Social Relations in the Roman World, ed. Michael Peachin. Oxford: Oxford University Press, 2011.

Waltke, Bruce. "Friends and Friendship in the Book of Proverbs: An Exposition of Proverbs 27:1-22", in CRUX Vol. XXXVIII, No 3, (2002).

Webb, David. "On Friendship: Derrida, Foucault, and the Practice of Becoming”, in Research in Phenomenology 33, (2003).

White, L. Michael. "Morality Between Two Worlds: A Paradigm of Friendship in Philippians", in David L. Balch, Everett Ferguson and Wayne A. Meeks (eds.), Greeks, Romans, and Christians: Essays in Honor of Abraham J. Malherbe. Minneapolis: Fortress, 1990.

White, L. Michael. "Rhetoric and Reality in Galatians: Framing the Social Demands of Friendship", in Early Christianity and Classical Culture: Comparative Studies in Honor of Abraham J. Malherbe. Leiden: Brill, 2003. 
Jurnal Theologia Aletheia Volume 20 No.15 September 2018131

Winter, Sean. "Friendship Traditions in the New Testament: An Overview", in Pacifica, Vol. 29 Issue 2, (2016).

Witherington III, Ben. Friendship and Finances in Philippi: The Letter of Paul to the Philippians. Harrisburg: Trinity Press International, 1994.

Zembylas, Michalinos. "Derrida, Foucault and critical pedagogies of friendship in conflict-troubled societies", in Discourse: Studies in the Cultural Politics of Education, Vo. 36, No. 1, (2015). 